\title{
Corrective Tibial Osteotomy in Young Adults Using an Intramedullary Nail
}

\author{
Kang-Il Kim, $\mathrm{MD}^{1}$, Peter H. Thaller, $\mathrm{MD}^{2}$, Alankar Ramteke, $\mathrm{MD}^{1}$, Sang Hak Lee, $\mathrm{MD}^{1}$, and \\ Seung-Hyuk Lee, $\mathrm{MD}^{1}$ \\ ${ }^{1}$ Department of Orthopaedic Surgery, Center for Joint Diseases and Rheumatism, Kyung Hee University Hospital at Gangdong, Seoul, Korea; ${ }^{2} 3 \mathrm{D}$ Surgery, Department \\ of Surgery, Clinical Center for University of Munich, Munich, Germany
}

\begin{abstract}
Purpose: The purpose of this study was to document results of a less invasive technique of open wedge proximal tibial osteotomy (PTO) for the varus knee in young adults using an intramedullary tibial nail.

Materials and Methods: We prospectively studied 24 knees in 16 young patients with varus knee deformity. The mean follow-up was 54 months (range, 36 to 107 months) and the mean age of patients at the time of operation was 25.8 years (range, 18 to 40 years). The open wedge PTO was performed below tibial tuberosity using a percutaneous multiple drill-hole technique. Conventional intramedullary tibial nail was used for fixation without bone graft. Radiographic evaluations were made using mechanical alignment (MA), posterior tibial slope angle, and Insall-Salvati ratio. Union time, loss of correction, implant failure, and associated complications were also investigated.

Results: The mean MA was significantly changed from $-9.7^{\circ}$ preoperatively to $1.1^{\circ}$ at the final follow-up ( $<<0.001$ ). There was no significant change in the proximal tibial anatomy and patellar height. All patients achieved radiographic bony union at an average of 3.1 months without loss of correction. The only complication was knee pain due to nail prominence in 3 patients.

Conclusions: Radiographic evaluation indicated that PTO using an intramedullary tibial nail leads to significant improvement in radiographic parameters without changes in posterior tibial slope or patellar height. We found that this technique could be a less invasive and effective alternative for correction of the varus knee in young adults.
\end{abstract}

Keywords: Knee, Tibia, Varus, Young adult, Corrective osteotomy, Intramedullary nailing

\section{Introduction}

Mechanical axis derangement arising out of either a varus or valgus deformity in the lower limb will subject the knee to accelerated degeneration and further deformity ${ }^{1-3)}$. Correction of these deformities is, therefore, essential and proximal tibial osteotomy (PTO) is advocated for young adults ${ }^{4,5)}$. In the recent literature,

Received January 15, 2014; Revised February 10, 2014;

Accepted March 10, 2014

Correspondence to: Sang Hak Lee, MD

Department of Orthopaedic Surgery, Center for Joint Diseases and

Rheumatism, Kyung Hee University Hospital at Gangdong, 892

Dongnam-ro, Gangdong-gu, Seoul 134-727, Korea

Tel: +82-2-440-6170, Fax: +82-2-440-6296

E-mail: sangdory@hanmail.net

This is an Open Access article distributed under the terms of the Creative Commons Attribution Non-Commercial License (http://creativecommons.org/licenses/by-nc/3.0/) which permits unrestricted non-commercial use, distribution, and reproduction in any medium, provided the original work is properly cited. many reports increasingly favor medial open wedge osteotomy over lateral close wedge osteotomy for correction of the varus $\mathrm{knee}^{6,7)}$. The level of osteotomy for those two techniques is usually above tibial tuberosity because this level of osteotomy has many advantages, including a high healing rate and the ability to correct the deformity closer to the joint ${ }^{8-10)}$. However, it has also several disadvantages, such as iatrogenic patella alta or baja, limited degree of correction, intraarticular fracture and limited proximal bone stock for rigid fixation ${ }^{8,11)}$.

There is no consensus in the literature on the optimal fixation device $^{12)}$ or a surgical technique for an open wedge osteotomy ${ }^{13)}$. Although plates ${ }^{12)}$ are commonly used for fixation of open wedge osteotomy, their biomechanical stability is still under investigation and longer and thicker plates are recommended ${ }^{14)}$. But relatively bigger plates need a larger incision and can cause irritation of thin overlying medial soft-tissue cover ${ }^{15)}$. There is a need, therefore, for a surgical technique characterized by less invasive surgical methods, biological osteotomy techniques, more rigid 
fixation, accelerated rehabilitation, and lower surgical risk of complications ${ }^{13,15}$. The purpose of this prospective study was to document results of PTO below the tibial tuberosity using an intramedullary nail in a consecutive series of young adults treated in our institute for varus deformity of the knee. We tried to incorporate the benefits of a conventional osteotomy with less invasive surgical method, less distortion of the anatomy of the proximal tibia, rigid fixation, and less morbidity. The first hypothesis was that open wedge PTO performed with a less invasive surgical approach and fixed with an intramedullary tibial nail in young adults with varus deformity would result in desired angular correction and facilitate union. The second hypothesis was that this technique would not affect proximal tibial anatomy, the patel- lofemoral joint, and basic knee biomechanics as measured by changes in posterior tibial slope angle (PTSA) and patellar height.

\section{Materials and Methods}

This is a prospective study consisting of a cohort of 24 consecutive cases in 16 patients treated for varus deformity of the knee by open wedge PTO fixed with an intramedullary tibial nail in our institute. All the patients got informed consent to participate in the study, and the study was approved by the Institutional Review Board. Young adults who visited our institute for concerns regarding bow knee deformity with associated symptoms, such as minor discomfort due to overloading of the medial compart-

Table 1. Patient Demographics, Preoperative Deformity and Postoperative Correction in Mechanical Alignment

\begin{tabular}{|c|c|c|c|c|c|c|c|c|c|c|c|}
\hline No. & Diagnosis & $\begin{array}{l}\text { Side } \\
(\mathrm{R} / \mathrm{L})\end{array}$ & $\begin{array}{l}\text { Age } \\
(\mathrm{yr})\end{array}$ & Sex & $\begin{array}{c}\text { PreMA } \\
\left({ }^{\circ}\right)\end{array}$ & $\begin{array}{c}\text { mLDFA } \\
\left({ }^{\circ}\right)\end{array}$ & $\begin{array}{l}\text { mMPTA } \\
\left({ }^{\circ}\right)\end{array}$ & $\begin{array}{l}\text { CORA } \\
(\mathrm{mm})\end{array}$ & $\begin{array}{l}\text { PostMA } \\
\quad\left({ }^{\circ}\right)\end{array}$ & $\begin{array}{l}\text { Last follow-up } \\
\text { MA }\left({ }^{\circ}\right)\end{array}$ & $\begin{array}{l}\text { Follow-up } \\
\text { (mo) }\end{array}$ \\
\hline 1 & Idiopathic genu varum & $\mathrm{L}$ & 19 & M & -5.0 & 86 & 82 & 80 & 7.5 & 7.4 & 41 \\
\hline & Idiopathic genu varum & $\mathrm{R}$ & 36 & $\mathrm{~F}$ & -4.0 & 89.7 & 89 & 28 & -2.8 & -3.0 & 105 \\
\hline & & $\mathrm{L}$ & 36 & $\mathrm{~F}$ & -6.2 & 93.1 & 88.5 & 44 & 4.9 & 4.8 & 105 \\
\hline 3 & $\begin{array}{l}\text { Genu varum left with posttraumatic } \\
\text { shortening right side }\end{array}$ & $\mathrm{L}$ & 18 & M & -6.9 & 90.5 & 87.8 & 48 & 1.0 & -0.3 & 37 \\
\hline 4 & Idiopathic genu varum & $\mathrm{R}$ & 23 & M & -10.4 & 90 & 83.8 & 73 & 3.0 & 3.3 & 36 \\
\hline \multirow[t]{2}{*}{5} & Multiple epiphyseal dysplasia & $\mathrm{R}$ & 22 & M & -6.1 & 89 & 78 & 121 & 3.0 & 2.7 & 36 \\
\hline & & $\mathrm{L}$ & 22 & M & -4.0 & 82 & 74 & 126 & 4.5 & 4.0 & 36 \\
\hline \multirow[t]{2}{*}{6} & Idiopathic genu varum & $\mathrm{R}$ & 26 & M & -9.5 & 89.4 & 80.8 & 98 & 0.0 & -0.3 & 40 \\
\hline & & $\mathrm{L}$ & 26 & M & -10.9 & 90.7 & 81.9 & 82 & 1.2 & 1.5 & 40 \\
\hline 7 & Idiopathic genu varum & $\mathrm{L}$ & 32 & M & -26.2 & 99.1 & 81.2 & 88 & -5.2 & -5.3 & 36 \\
\hline \multirow[t]{2}{*}{8} & Idiopathic genu varum & $\mathrm{R}$ & 27 & $\mathrm{~F}$ & -16.7 & 100.7 & 85.8 & 60 & 2.2 & 2.4 & 54 \\
\hline & & $\mathrm{L}$ & 29 & $\mathrm{~F}$ & -21.0 & 103.8 & 80 & 112 & 1.1 & 1.3 & 36 \\
\hline 9 & Hemophilic arthropathy & $\mathrm{R}$ & 24 & M & -5.0 & 86 & 85.4 & 64 & 0.6 & 1.0 & 37 \\
\hline 10 & Idiopathic genu varum & $\mathrm{R}$ & 23 & M & -12.0 & 80 & 68 & 134 & 3.0 & 2.6 & 36 \\
\hline \multirow[t]{2}{*}{11} & Idiopathic genu varum & $\mathrm{R}$ & 24 & $\mathrm{~F}$ & -12.0 & 91 & 84 & 70 & 2.0 & 2.4 & 36 \\
\hline & & $\mathrm{L}$ & 23 & $\mathrm{~F}$ & -12.0 & 91 & 82 & 81 & 2.0 & 2.6 & 36 \\
\hline 12 & Idiopathic genu varum & $\mathrm{R}$ & 40 & $\mathrm{~F}$ & -10.9 & 86.5 & 79.3 & 115 & 0.1 & 0.3 & 45 \\
\hline \multirow[t]{2}{*}{13} & Idiopathic genu varum & $\mathrm{R}$ & 21 & $\mathrm{~F}$ & -8.7 & 93.1 & 80.5 & 106 & 0.23 & 0.3 & 39 \\
\hline & & $\mathrm{L}$ & 20 & $\mathrm{~F}$ & -10.5 & 92.6 & 81.6 & 84 & -6.0 & -5.0 & 48 \\
\hline \multirow[t]{2}{*}{14} & Idiopathic genu varum & $\mathrm{R}$ & 20 & $\mathrm{~F}$ & -7.2 & 91.2 & 85.9 & 53 & 0.5 & 0.6 & 67 \\
\hline & & $\mathrm{L}$ & 20 & $\mathrm{~F}$ & -6.1 & 91.4 & 86.3 & 51 & -1.5 & -1.3 & 67 \\
\hline 15 & Idiopathic genu varum & $\mathrm{L}$ & 40 & F & -11.69 & 93.8 & 84.9 & 68 & -2.1 & -2.4 & 69 \\
\hline \multirow[t]{3}{*}{16} & Idiopathic genu varum & $\mathrm{R}$ & 24 & M & -4.2 & 86 & 84 & 71 & 2.8 & 2.7 & 107 \\
\hline & & $\mathrm{L}$ & 24 & M & -5.2 & 85 & 81 & 92 & 3.7 & 3.9 & 107 \\
\hline & Mean & & 25.8 & & -9.7 & 90.5 & 82.3 & 81 & 1.1 & 1.1 & 54.0 \\
\hline
\end{tabular}

R: right, L: left, MA: mechanical alignment (hip-knee-ankle axis), mLDFA: mechanical lateral distal femoral angle, mMPTA: mechanical medial proximal tibial angle, CORA: center of rotation of angulation. 
ment, with no or mild early degenerative changes on radiographs were included. Our indication for PTO using an intramedullary nail were 1) varus malalignment on long-standing radiographs ${ }^{16)}$ in young active individuals under 40 years of age, 2) patients with a normal knee range of motion, 3) the mechanical axis passing through a point located at $30 \%$ or less on the articular surface where medial edge of articular surface is $0 \%$ and lateral edge is $100 \%{ }^{17,18)}$, and 4) stable knee. The exclusion criteria were 1) patients older than 40 years of age, 2) patients with advanced arthritic changes ${ }^{19)}$, 3) patellofemoral pain, and 4) indications for simultaneous ligament repair. For the open wedge PTO, a conventional intramedullary tibial nail was used (CTN-Cannulated Tibia Nail [Synthes, Oberdorf, Switzerland] in 14 cases, ETN- Expert Tibia Nail [Synthes] in 4 cases and Targon T-Universal Tibia nail [B. Braun, Melsungen, Germany] in 6 cases). There were 9 male and 7 female patients. The underlying cause of deformity was idiopathic genu varum in 13 patients, and the other diagnoses were, multiple epiphyseal dysplasia, hemophilic knee arthropathy, and post-traumatic deformity in one patient each (Table 1). The mean age of patients at the time of operation was $25.8 \pm 6.5$ years (range, 18 to 40 years). The average follow-up period was 54 months (range, 36 to 107 months). With regard to grading according to the radiographic appearance, 20 knees were grade
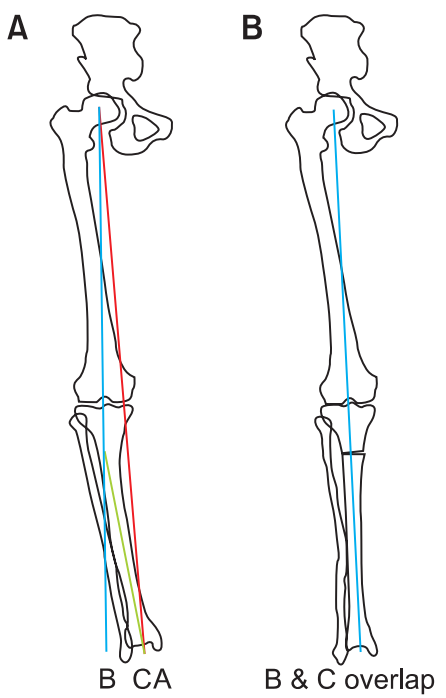

Fig. 1. (A) Three lines were marked on long leg radiographs during preoperative planning. The mechanical axis was marked as line A (red line), the corrected mechanical axis as was marked as line B (blue line), and line C (green line) denoted mid-diaphyseal line of the distal fragment. (B) Paper tracing was divided at the level of osteotomy and distal tibia was moved to realign line $\mathrm{C}$ along line $\mathrm{B}$. As line $\mathrm{C}$ overlapped the corrected mechanical axis (line B), valgus opening was created at the osteotomy site achieving deformity correction. The trajectory of the nail in the proximal tibia was in valgus direction.
0 and 4 knees were grade 1 by Kellgren-Lawrence classification. Three patients also underwent other procedures for associated deformities before osteotomy. One patient underwent bilateral periacetabular rotational osteotomy for dysplastic hip, another patient underwent bilateral supracondylar femoral osteotomy for varus bowing of femurs, and the third patient underwent lengthening with a ring fixator for post-traumatic shortening and deformity in the other leg.

The weight bearing line was drawn on long leg weight bearing radiographs, connecting centers of the hip and ankle ${ }^{9)}$. If the medial edge of articular surface is $0 \%$ and lateral edge is $100 \%, 4,17,18$, the weight bearing line in present series always passed medial to a point denoting 50\%. The average position of weight bearing line was at $10.7 \%$ (range, $-26.5 \%$ to $29.5 \%$ ). To determine the mechanical alignment (MA) of the limb, hip-knee-ankle (HKA) angle ${ }^{20)}$ of the lower extremity was calculated as the angle between the femoral and tibial mechanical axis ${ }^{9}$. Limb deformity was expressed as degrees of deviation of HKA from $180^{\circ}$, hence forth referred to as MA, with varus deviations as negative (-) and valgus deviations as positive $(+)$.

In the preoperative planning, a corrected mechanical axis was drawn passing through the center of the hip and the center of the knee on long leg radiographs (Fig. 1A). As all of the patients were active and young adults with few symptoms associated with deformity and minimal degenerative changes, we aimed to correct the mechanical axis of the lower extremity from varus to neutral or slight valgus position of $3^{\circ}$ rather than over correction ${ }^{9,21)}$. When this line was extended over the tibia, it passed from the medial side of the tibial plateau to the lateral side of the proximal tibial metaphysis. The path of this line on the proximal tibia was used for nail entry and direction of the nail path. Therefore, the nail entry point was located medially compared to conventional intramedullary nailing for tibial fracture. Usually, the level of osteotomy was just above where the line contacts the lateral tibial cortex. Furthermore, the level of osteotomy was influenced by the location of the most distal screw hole for proximal interlocking present on the nail; it was usually at a point 1 to $2 \mathrm{~cm}$ below the most distal screw hole for proximal interlocking on the nail. The mid-diaphyseal line of the distal fragment of the tibia was marked on a paper tracing and aligned with the proximal nail path to achieve desired correction such that the mid-diaphyseal line of the divided distal tibia coincided with the corrected mechanical axis (Fig. 1B).

All surgeries were performed by the senior author. The level of osteotomy and direction of the nail were marked on the leg under fluoroscopic guidance according to the preoperative draw- 

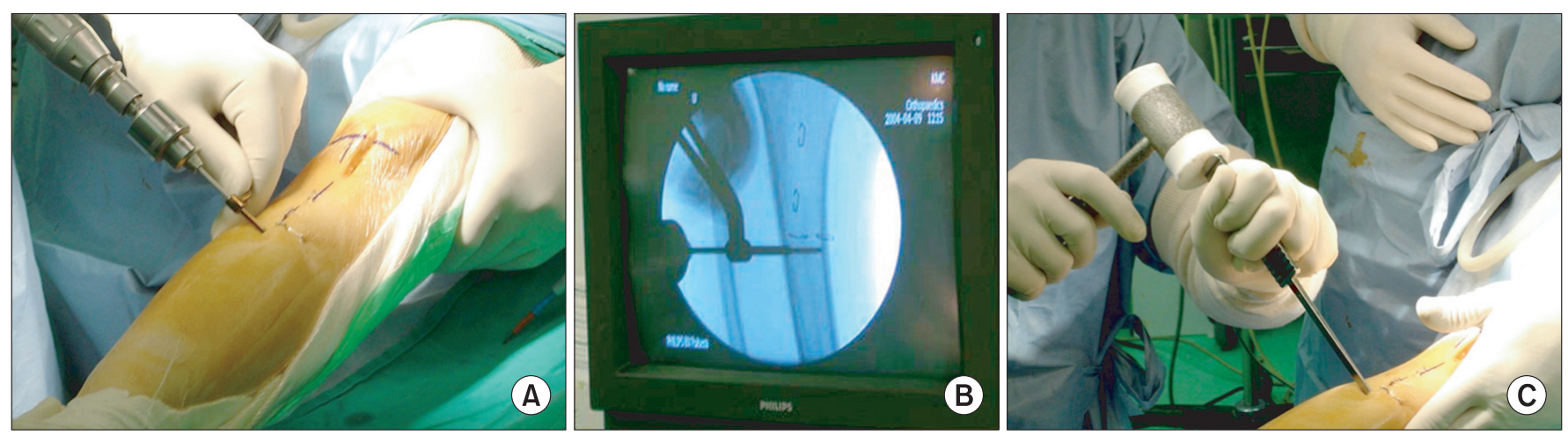

Fig. 2. Osteotomy was performed through a small stab incision from the antero-lateral surface of the tibia by percutaneous drilling. (A) A drill sleeve for soft tissue protection was used. (B) Multiple drill holes (usually 8 holes) were made in the same plane under fluoroscopic guidance at the level of osteotomy. (C) A 0.25 inch osteotome was used to connect most of the drill holes through the same skin incision.

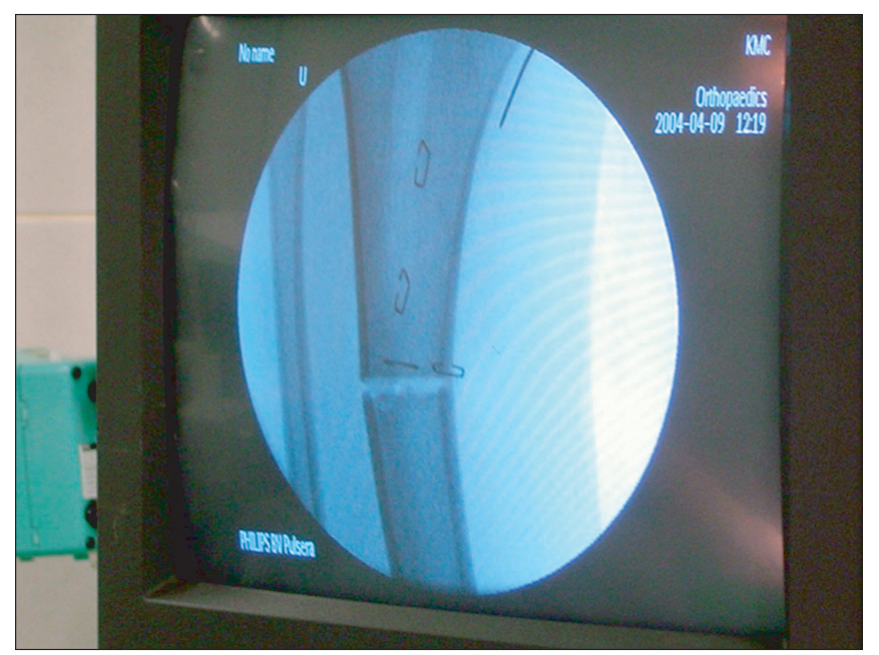

Fig. 3. Osteotomy was completed with gentle manual force without displacement, and the fragments were still aligned to each other. Any changes in the alignment either varus or valgus direction was possible at this stage with minimum force.

ing. The entry point of the tibial intramedullary nail was made through a less than $3 \mathrm{~cm}$ skin incision medial to the patellar tendon. Only the proximal tibia above the planned osteotomy line was reamed under fluoroscopic guidance along the desired trajectory of the entry of nail in the proximal fragment. Then osteotomy was performed percutaneously ${ }^{22)}$ through a small stab incision $(<1 \mathrm{~cm})$ on the antero-lateral surface of the tibia (Fig. 2A). Under fluoroscopic control, multiple transverse drill holes were made with a $3.2 \mathrm{~mm}$ drill bit with a low-speed to minimize heat generation (Fig. 2B). A 0.25 inch osteotome was then used to connect most of the drill holes and the osteotomy was completed using gentle manual force ${ }^{22}$ (Fig. 3). Then, a guide wire was passed through the medullary canal and reaming was performed in gradually increasing increments of $0.5 \mathrm{~mm}$. We over-

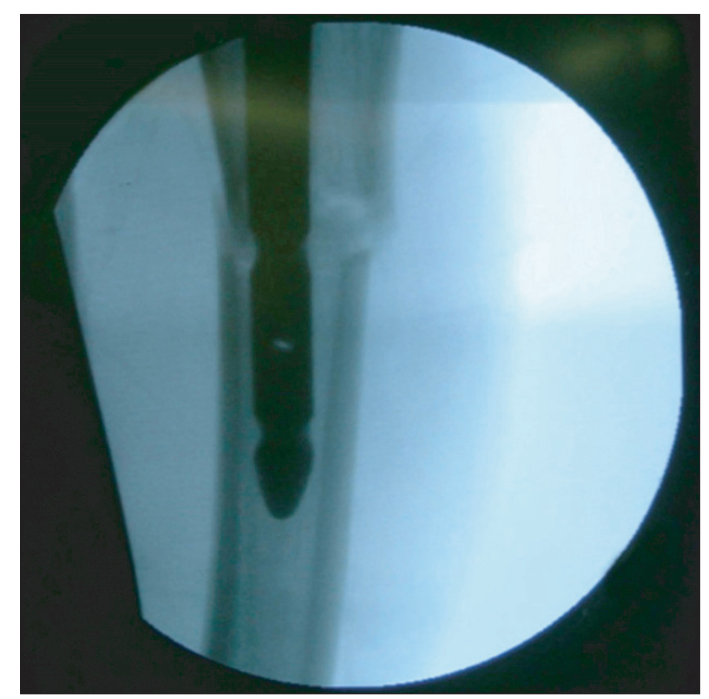

Fig. 4. A valgus correction with medial opening was automatically created simultaneously with passing of the nail across the osteotomy site into the mid-diaphysis in the distal tibia.

reamed the medullary canal by $0.5 \mathrm{~mm}$ before determining a nail of proper size.

The nail was naturally inserted manually through the medially located entry point with free hand without the use of any blocking screws to guide the passage of the nail. When the nail engaged the medullary canal and isthmus distal to the osteotomy level, the distal fragment was automatically corrected into neutral alignment (Fig. 4). This correction was achieved by a medial opening at the osteotomy site, valgus tilting of the distal fragment, and lateral translation of the distal fragment ${ }^{23)}$. No bone graft was performed in all cases. This nail was securely fixed with 2 or 3 proximal and distal interlocking screws. Concomitant osteotomy of the fibula can be performed before tibial osteotomy in case of severe varus, but we did not perform a fibular osteotomy (Fig. 5). 

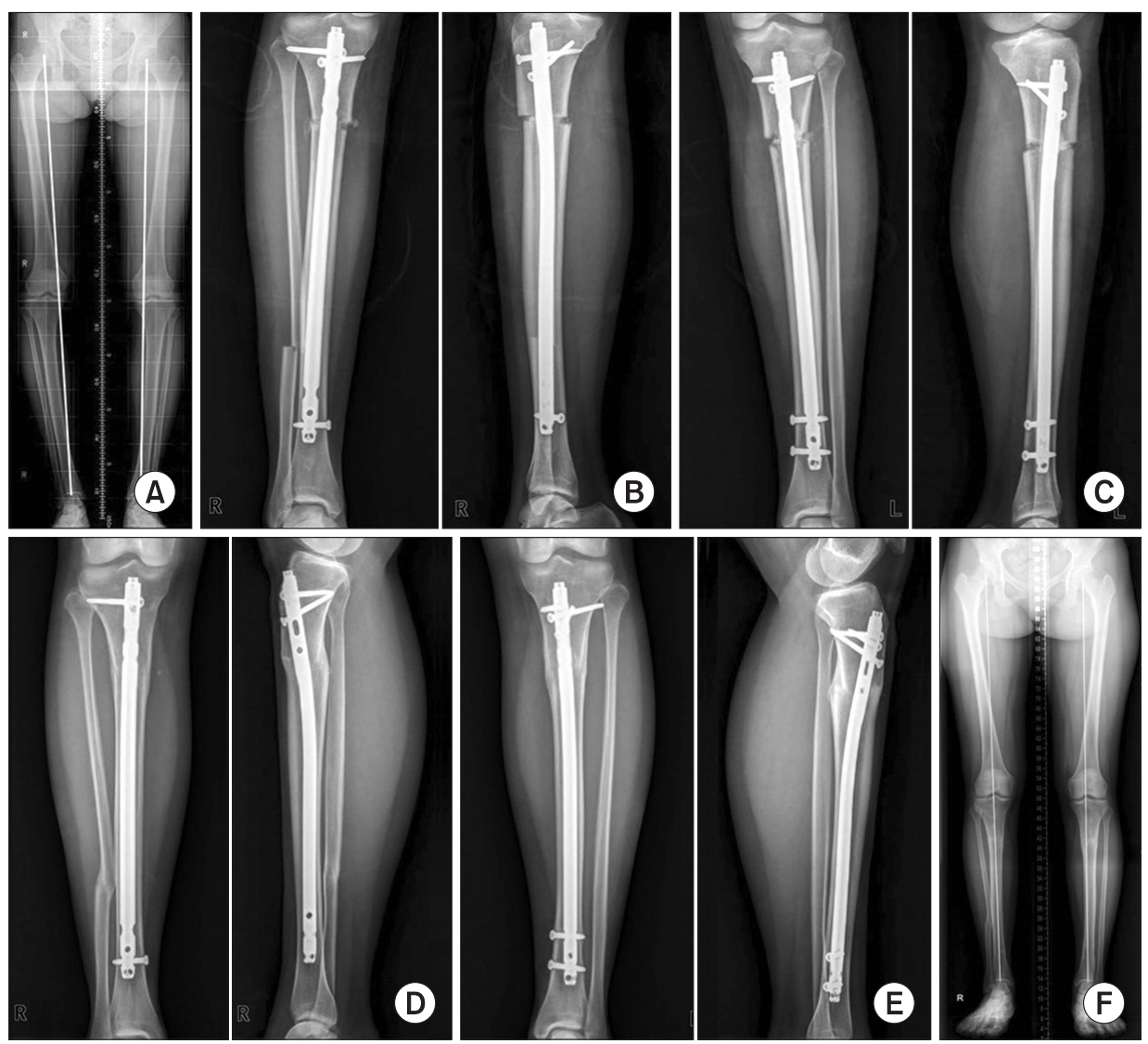

Fig. 5. A 20-year-old female patient having idiopathic bilateral genu varum deformity complained mild discomfort and wanted deformity correction. (A) Preoperative long leg standing radiograph showed varus deformity. The mechanical alignment (MA) of right side was $-7.2^{\circ}$ and femorotibial angle (FTA) was $-2.5^{\circ}$, the left side MA was $-6.1^{\circ}$ and FTA was $-0.1^{\circ}$. $(\mathrm{B}, \mathrm{C})$ This patient was operated for deformity correction by proximal tibial osteotomy using an intramedullary nail and concomitant fibular osteotomy was performed on the right side. (D, E) Correction was achieved and MA was corrected to $0.5^{\circ}$ valgus on the operated side. At 32 months follow-up just before the implant removal, solid union and good alignment could be seen at the osteotomy site of both legs. (F) At the last follow-up of 67 months after osteotomy, the long leg standing radiograph showed maintenance of good alignment and no correction loss.
On the first postoperative day, the patient was allowed bed-side leg dangling and wheel chair mobilization. Walking with partial weight bearing was started on postoperative day 2 with gradual weight bearing as tolerated.

On preoperative radiographic evaluation, the level of deformity was determined in all cases by identifying the center of the rotation of angulation (CORA $)^{23)}$. Mechanical lateral distal femoral angle (mLDFA) (normal range, $86^{\circ}$ to $90^{\circ}$ ) and mechanical medial proximal tibial angle (mMPTA) (normal range, $85^{\circ}$ to $89^{\circ}$ ) were measured on radiographs preoperatively to assess the contribution of the distal femur and proximal tibia in the origin of the knee varus deformity ${ }^{24)}$. Preoperative MA and PTSA were recorded radiographically ${ }^{9)}$. Changes in MA and PTSA were noted on each visit till the latest follow-up. Changes in the patellar height using Insall-Salvati (IS) ratio ${ }^{11)}$ were recorded. Digital imaging system ( $\pi$ ViewSTAR; Infinitt, Seoul, Korea) was used for radiographic evaluation ${ }^{20)}$. Radiographic evaluation was performed by two individuals who were blinded to the results. To evaluate inter-observer validity, we compared radiographic results that were obtained by two different researchers. The level of agreement was tested by Kappa statistics $(k=0.85, \mathrm{p}<0.001)$ which we considered highly reasonable. Limb length and range of motion were recorded preoperatively and postoperatively at each follow-up visit. Time to bony union, pain after healing, scar of surgery, implant failure and other complications were studied postoperatively and at each subsequent follow-up visit. We performed all statistical analyses using SPSS ver. 12.0 (SPSS Inc., Chicago, IL, USA). Comparisons between preoperative and postoperative values were made. Significance was tested using Student's t-test, assuming normal distribution of population. A two tailed p-value from paired t-test were calculated for $95 \%$ confidence intervals.

\section{Results}

In all cases, the level of deformity was within the proximal tibia, when the CORA was determined. The average location of CORA was $81 \pm 31 \mathrm{~mm}$ (range, 28 to $134 \mathrm{~mm}$ ) from the joint orientation line. The CORA was located within less than $50 \mathrm{~mm}$ of the joint orientation line in 3 cases (12.5\%), within $50-100 \mathrm{~mm}$ of the joint orientation line in 15 cases (62.5\%), and within 100$134 \mathrm{~mm}$ from the joint orientation line in the remaining 6 cases (25.0\%). The level of osteotomy was an average of $83 \pm 5.3 \mathrm{~mm}$ (range, 75 to $90 \mathrm{~mm}$ ) below the joint line. On the assessment of 
Table 2. Preoperative, Postoperative and Latest Follow-up Values of MA, PTSA, and IS Ratio

\begin{tabular}{lccc}
\hline Parameter & Preoperative & Postoperative & Last follow-up \\
\hline MA $\left(^{\circ}\right)$ & $-9.7 \pm 5.6$ (range, -26.2 to -1.8$)$ & $1.1 \pm 3.1$ (range, -6 to 7.5$)$ & $1.1 \pm 2.9$ (range, -5.3 to 7.4$)$ \\
& & $\mathrm{p}<0.001$ & $\mathrm{p}=0.83$ \\
PTSA $\left({ }^{\circ}\right)$ & $9.77 \pm 4.54$ (range, 4.42 to 18.2$)$ & $9.31 \pm 4.81$ (range, 4.64 to 17.66$)$ & $9.29 \pm 4.91$ (range, 4.52 to 17.85$)$ \\
& & $\mathrm{p}=0.462$ & $\mathrm{p}=0.956$ \\
IS ratio & $1.17 \pm 0.08$ (range, 1.08 to 1.23$)$ & $1.16 \pm 0.06$ (range, 1.04 to 1.33$)$ & $1.18 \pm 0.06$ (range, 1.08 to 1.32$)$ \\
& & $\mathrm{p}=0.175$ & $\mathrm{p}=0.684$ \\
\hline
\end{tabular}

Values are presented as mean \pm standard deviation (range).

MA: mechanical alignment (hip-knee-ankle axis), PTSA: posterior tibial slope angle, IS: Insall-Salvati.

the origin of deformity, the mean mLDFA was $90.5^{\circ}$ (range, $80^{\circ}$ to $103.8^{\circ}$ ) and the mean MMPTA was $82.3^{\circ}$ (range, $68^{\circ}$ to $\left.89^{\circ}\right)^{24)}$ (Table 1). All osteotomies healed without delay or non-union. The average healing time to bony union was 3.1 months (range, 2 to 4.5 months). The average MA in all the patients was significantly improved from deformed position to corrected position (Table 2). Considering our aim of correction was between neutral to $3^{\circ}$ valgus in MA, 9 cases (37.5\%) were outliers. There were 5 knees with under correction (less than neutral angle) and 4 knees with over correction (more than $3^{\circ}$ valgus). The postoperative correction was maintained till the latest follow-up and there was no loss of correction. There was no significant change in the preoperative values of the PTSA or IS ratio, either postoperatively or at the latest follow-up (Table 2).

The leg length changed from an average of $35.1 \pm 2.7 \mathrm{~cm}$ (range, 30.4 to $39 \mathrm{~cm}$ ) to an average of $36.2 \mathrm{~cm}$ (range, 31.2 to $39.1 \mathrm{~cm}$ ) postoperatively $(\mathrm{p}<0.001)$. The average increase in leg length was $1.1 \pm 0.6 \mathrm{~cm}$ (range, -0.1 to $2.2 \mathrm{~cm}$ ). All patients maintained full preoperative knee range of motion till the latest follow-up. The average duration to crutch off and walking with full weight bearing was 8 weeks (range, 6 to 11 weeks). No patient complained of pain over scar. All postoperative scars were rated for cosmetic appearance on a categorical scale ${ }^{25}$. All the postoperative scars were "adequate" defined as visible but not wide or hypertrophic or "excellent" defined as faint or not evident, except 2 patients who developed hypertrophic scars. The scar of the entry of nail was smaller than $3 \mathrm{~cm}$ in length and the scars of osteotomy and interlocking were less than $1 \mathrm{~cm}$ each in all cases. Fifteen knees underwent implant removal during the follow-up period following solid union at an average of 31 months (range, 26 to 48 months) after the surgery. Implant removal was done for the patients who requested to have implant removed over 2 years after surgery. We could not remove the nails in one patient with bilateral correction who visited to remove the nails at 107 months after the operation since solid bone connection occurred through the slid- ing slot of the nail. Three patients complained of anterior knee pain due to nail prominence. In two patients, implant removal after union led to pain relief. Third patient was relieved of pain when the prominent implant sunk inside further after removal of interlocking screws. One patient had intraarticular loose-bodies, discoid lateral meniscus, and torn medial meniscus which was treated arthroscopically for pain relief. No other complications, such as nerve or vascular injury, intra-articular or lateral tibial plateau fracture, delayed wound healing, infection or implant insufficiency, were seen.

\section{Discussion}

The most important finding of the present study is that PTO below tibial tuberosity using an intramedullary nail can successfully achieve bony union and correction of coronal malalignment in young adults with varus knee. Osteotomy was performed by multiple percutaneous drill-hole technique that could minimize injury to periosteum and surrounding soft tissue. Intramedullary nail without bone graft was preferred for fixation for advantages, such as shorter union and rehabilitation time and prompt resumption of joint movement and function. The level of osteotomy below the tibial tuberosity in our novel technique was compatible with the use of an intramedullary nail and caused minimal changes in the anatomy of the proximal tibia besides other advantages. All osteotomies healed without collapse, and the only complication was nail prominence in 3 patients.

Although plates are commonly used for fixation in PTO, there is no consensus in the literature on the optimal fixation device. This study addresses an alternative procedure of less invasive PTO below tibial tuberosity using an intramedullary nail, which was developed by the authors for correction of a varus knee in young adults. Improper surgical technique after nailing of tibial fractures leads to angular deformity due to a mismatch between the nail axis in the proximal segment and the distal segment that 
contains isthmus ${ }^{26)}$. This mismatch is primarily due to a far too medial starting point, such as a medial para-patellar incision leading to a medial entry site. The musculature of the anterior compartment acts as a tether and contributes to valgus by creating a gap between two fragments leading to a medial opening of the fracture. This complication was studied closely and reproduced in a controlled manner for deformity correction by the authors.

The level of PTO compatible with an intramedullary nail fixation should be below the level of proximal locking screws. Therefore, the level of osteotomy for our novel technique was below the tibial tuberosity. This level has several advantages ${ }^{27,28)}$ including greater degree of correction and preservation of the proximal tibial anatomy ${ }^{28}$. The large proximal fragment decreases the chances of avascular necrosis and iatrogenic tibial plateau fracture which can occur in a conventional medial opening wedge osteotomy ${ }^{28}$. There is no injury to the patellar tendon ${ }^{27,28)}$ and patella baja is less likely to occur. This may aid during a subsequent total knee arthroplasty (TKA) for osteoarthritic patients ${ }^{27,28}$. However, the possible disadvantage is low healing rates ${ }^{28)}$ associated with any osteotomy through cortical bone. As healing also depends on surgical exposure and dissection ${ }^{22}$, osteotomy was performed by percutaneous drill holes ${ }^{22)}$ and was completed using gentle manual force. Power saw and high-speed drills used in conventional techniques can cause thermal necrosis of bone ends and adjacent soft tissues ${ }^{22}$. Therefore, we avoided power saw and used a new drill bit each time over a low speed drill to minimize heat generation while producing a linear undisplaced fracture for osteotomy. Due to minimally invasive surgical technique, periosteum and soft tissue were relatively well protected, with periosteum being the most important contributor to bone healing ${ }^{22}$. All the cases in our series were united without any delay or non-union. The advantages of percutaneous drilling through a $<1 \mathrm{~cm}$ stab incision included not only facilitated healing but also cosmesis in young adults.

Various correction goals have been recommended by different authors. Our study only included patients younger than 40 years of age and without arthritic changes or symptoms. In PTO for degenerative osteoarthritis, overcorrection of the varus deformity to valgus is generally recommended as their aim is essentially to transfer the weight to less affected regions ${ }^{8,21}$. Several studies have shown that overcorrection is not indicated in young patients, if there is no medial tibiofemoral joint damage and the cartilage is not completely worn down ${ }^{9,29)}$. We achieved correction from a mean MA of $-9.7^{\circ}$ to $1.1^{\circ}$ postoperatively and correction was maintained as evidenced by a mean MA of $1.1^{\circ}$ at the latest follow-up. We believe a nail with multiplanar locking options and bicortical purchase of the proximal screws could help avoid loss of correction in this cohort. We recommend that this technique be considered in relatively young patients with genu varum.

Studies have demonstrated that significant change in PTSA following open wedge osteotomy is related to the triangular shape of the proximal tibia ${ }^{8,18}$. Several researchers revealed that changes in the angle of inclination of the tibial plateau cause instability and that excessive tibial translation in the sagittal plane might cause progression of osteoarthritis ${ }^{30}$. In the present study, the mean PTSA did not change significantly at the latest follow-up (range, $9.77^{\circ}$ to $9.29^{\circ} ; \mathrm{p}>0.05$ ). The osteotomy level in this series was quite lower than the usual level ${ }^{4,11)}$ at the metaphysio-diaphyseal junction or very proximal diaphysis. This made the osteotomy less vulnerable to an increase in PTSA that can be caused by muscular forces or natural increases after conventional opening or closed wedge osteotomies.

Recent studies have demonstrated that a decrease in patellar height associated with medial open wedge PTO is due to distalization of the tibial tuberosity and shortening of the patella tendon by scarring ${ }^{4,18}$. These results can cause high incidence of patella baja following PTO, which may have deleterious effects on the patellofemoral biomechanics or complicate subsequent $\mathrm{TKA}^{11)}$. In our series, the change in IS ratio from $1.17 \pm 0.08$ to $1.16 \pm 0.06$ was not significant. Therefore, we believe that the amount of change in the patella height is smaller for PTO below the level of the patella tendon.

There are some limitations of our technique and study. First, the number of patients was relatively small and it was not a comparative study. Consequently, we cannot state that our technique produces better result than other PTO techniques for genu varum. Second, no clinical or pain scores were assessed since most of our young patients showed only minor discomfort or even no pain. Thus, a longer follow-up of this cohort of patients seems necessary. Third, this method is technically demanding and has a steep learning curve because the rate of outlier was relatively high. The degree of correction of the varus deformity at the metaphyseal/ diaphyseal junction is critically determined by the precise identification of the nail entry portal, the nail path, and the adequacy of locking screws. Therefore, preoperative planning is extremely important to determine exact degree of correction, entry point, and the trajectory of the nail in the proximal fragment.

\section{Conclusions}

Radiographic evaluation indicated that PTO using an intramed- 
ullary tibial nail leads to significant improvement in radiographic parameters without changes in the posterior tibial slope or patellar height. We found that this technique could be a less invasive and effective alternative for correction of the varus knee in young adults.

\section{Conflict of Interest}

No potential conflict of interest relevant to this article was reported.

\section{References}

1. Lee DC, Byun SJ. High tibial osteotomy. Knee Surg Relat Res. 2012;24:61-9.

2. Lee SC, Jung KA, Nam CH, Jung SH, Hwang SH. The shortterm follow-up results of open wedge high tibial osteotomy with using an Aescula open wedge plate and an allogenic bone graft: the minimum 1-year follow-up results. Clin Orthop Surg. 2010;2:47-54.

3. Marti RK, Verhagen RA, Kerkhoffs GM, Moojen TM. Proximal tibial varus osteotomy: indications, technique, and five to twenty-one-year results. J Bone Joint Surg Am. 2001;83:164-70.

4. Noyes FR, Mayfield W, Barber-Westin SD, Albright JC, Heckmann TP. Opening wedge high tibial osteotomy: an operative technique and rehabilitation program to decrease complications and promote early union and function. Am J Sports Med. 2006;34:1262-73.

5. Shim JS, Lee SH, Jung HJ, Lee HI. High tibial open wedge osteotomy below the tibial tubercle: clinical and radiographic results. Knee Surg Sports Traumatol Arthrosc. 2013;21:5763.

6. Iorio R, Pagnottelli M, Vadala A, Giannetti S, Di Sette P, Papandrea P, Conteduca F, Ferretti A. Open-wedge high tibial osteotomy: comparison between manual and computerassisted techniques. Knee Surg Sports Traumatol Arthrosc. 2013;21:113-9.

7. Madry H, Ziegler R, Orth P, Goebel L, Ong MF, Kohn D, Cucchiarini M, Pape D. Effect of open wedge high tibial osteotomy on the lateral compartment in sheep. Part I: analysis of the lateral meniscus. Knee Surg Sports Traumatol Arthrosc. 2013;21:39-48.

8. Bombaci H, Canbora K, Onur G, Gorgec M. The effect of open wedge osteotomy on the posterior tibial slope. Acta Orthop Traumatol Turc. 2005;39:404-10.
9. Pape D, Rupp S. Preoperative planning for high tibial osteotomies. Oper Tech Orthop. 2007;17:2-11.

10. Staubli AE, De Simoni C, Babst R, Lobenhoffer P. TomoFix: a new LCP-concept for open wedge osteotomy of the medial proximal tibia: early results in 92 cases. Injury. 2003;34 Suppl 2:B55-62.

11. Brouwer RW, Bierma-Zeinstra SM, van Koeveringe AJ, Verhaar JA. Patellar height and the inclination of the tibial plateau after high tibial osteotomy. The open versus the closedwedge technique. J Bone Joint Surg Br. 2005;87:1227-32.

12. Stoffel K, Stachowiak G, Kuster M. Open wedge high tibial osteotomy: biomechanical investigation of the modified Arthrex Osteotomy Plate (Puddu Plate) and the TomoFix Plate. Clin Biomech (Bristol, Avon). 2004;19:944-50.

13. Olin MD, Vail TP. High tibial osteotomy: will new techniques provide better results? Curr Opin Orthop. 2001;12:812

14. Agneskirchner JD, Freiling D, Hurschler C, Lobenhoffer P. Primary stability of four different implants for opening wedge high tibial osteotomy. Knee Surg Sports Traumatol Arthrosc. 2006;14:291-300.

15. Galla M, Lobenhoffer p. High tibial open wedge valgus osteotomy stabilized with the tomofix? Plate fixator. Oper Orthop Traumatol 2004;16:397-417.

16. Machen MS, Stevens PM. Should full-length standing anteroposterior radiographs replace the scanogram for measurement of limb length discrepancy? J Pediatr Orthop B. 2005;14:30-7.

17. Dugdale TW, Noyes FR, Styer D. Preoperative planning for high tibial osteotomy. The effect of lateral tibiofemoral separation and tibiofemoral length. Clin Orthop Relat Res. 1992;(274):248-64.

18. Kim SJ, Mahajan RH, Park KY, Kim TE, Lee DH, Choi WJ. Biplanar medial open-wedge high tibial osteotomy for medial compartment osteoarthritis of the knee: a novel technique and follow-up. Oper Tech Orthop 2007;17:29-37.

19. Kellgren JH, Lawrence JS. Radiological assessment of osteoarthrosis. Ann Rheum Dis. 1957;16:494-502.

20. Cooke TD, Sled EA, Scudamore RA. Frontal plane knee alignment: a call for standardized measurement. J Rheumatol. 2007;34:1796-801.

21. Hernigou P, Medevielle D, Debeyre J, Goutallier D. Proximal tibial osteotomy for osteoarthritis with varus deformity: a ten to thirteen-year follow-up study. J Bone Joint Surg Am. 1987;69:332-54.

22. Paley D, Tetsworth K. Percutaneous osteotomies. Osteo- 
tome and Gigli saw techniques. Orthop Clin North Am. 1991;22:613-24.

23. Paley D, Herzenberg JE, Tetsworth K, McKie J, Bhave A. Deformity planning for frontal and sagittal plane corrective osteotomies. Orthop Clin North Am. 1994;25:425-65.

24. Gordon JE, King DJ, Luhmann SJ, Dobbs MB, Schoenecker PL. Femoral deformity in tibia vara. J Bone Joint Surg Am. 2006;88:380-6.

25. Quinn JV, Drzewiecki AE, Stiell IG, Elmslie TJ. Appearance scales to measure cosmetic outcomes of healed lacerations. Am J Emerg Med. 1995;13:229-31.

26. Lang GJ, Cohen BE, Bosse MJ, Kellam JF. Proximal third tibial shaft fractures. Should they be nailed? Clin Orthop Relat Res. 1995;(315):64-74.
27. Gaasbeek RD, Sonneveld H, van Heerwaarden RJ, Jacobs WC, Wymenga AB. Distal tuberosity osteotomy in open wedge high tibial osteotomy can prevent patella infera: a new technique. Knee. 2004;11:457-61.

28. Preston CF, Fulkerson EW, Meislin R, Di Cesare PE. Osteotomy about the knee: applications, techniques, and results. J Knee Surg. 2005;18:258-72.

29. Hernigou P. Open wedge tibial osteotomy: combined coronal and sagittal correction. Knee. 2002;9:15-20.

30. Lustig S, Scholes CJ, Costa AJ, Coolican MJ, Parker DA. Different changes in slope between the medial and lateral tibial plateau after open-wedge high tibial osteotomy. Knee Surg Sports Traumatol Arthrosc. 2013;21:32-8. 